\title{
Selective removal of mercury from aqueous solutions using thiolated cross-linked polyethylenimine
}

\author{
Dalia M. Saad • Ewa M. Cukrowska • \\ Hlanganani Tutu
}

Received: 5 December 2012 / Accepted: 25 March 2013/Published online: 4 April 2013

(c) The Author(s) 2013. This article is published with open access at Springerlink.com

\begin{abstract}
A successful approach to develop an insoluble form of polyethylenimine with a thiol-based functional group for selective removal of $\mathrm{Hg}$ (II) from aqueous solutions is reported. The selectivity of the modified polymer for $\mathrm{Hg}$ (II) as well as its ability to be regenerated for re-use has been studied. The synthesised polymer exhibited high selectivity for $\mathrm{Hg}$ (II) with high removal efficiency of up to $97 \%$, even in the presence of competing ions. The Freundlich isotherm was found to best fit and describe the experimental data. The pseudo-second-order equation explains the adsorption kinetics most effectively implying chemisorption. The thermodynamic study of the adsorption process revealed high activation energies $>41 \mathrm{~kJ} \mathrm{~mol}^{-1}$, further confirming chemisorption as the mechanism of interaction between mercury ions and the polymer surface. The polymer exhibited good potential for re-use after many cycles of regeneration, giving good removal efficiency up to the fifth cycle.
\end{abstract}

Keywords Adsorption - Mercury · Thiolation ·

Selective removal

\section{Introduction}

Industrial development has left pronounced effects on the environment generally and on water resources specifically. Many industries generate waste products that contain high concentrations of heavy metals which are discharged directly or indirectly into water systems (Hang et al. 2009;

D. M. Saad · E. M. Cukrowska $(\bowtie) \cdot$ H. Tutu

Molecular Sciences Institute, School of Chemistry, University of the Witwatersrand, Johannesburg, South Africa

e-mail: ewa.cukrowska@wits.ac.za
Velea et al. 2008; Zhuang et al. 2009). In South Africa, the mining industry accounts for the largest portion of heavy metal contamination through acid mine drainage (AMD). The removal of these toxic metal ions is an important challenge taking into account that the current methods of remediating contaminated water such as ion-exchange resin, electrolytic or liquid extraction, electrodialysis, chemical precipitation, membrane filtration, and biosorption are sometimes inadequate due to the large quantities of these wastes, resulting in metal-bearing sludges which are difficult to dispose of. Furthermore, most of these traditional methods are expensive. Therefore, there is an urgent need for new feasible and cost effective methods (Ahmed et al. 2008; Ghoul et al. 2003).

There is also a need for such methods to be manipulated for effectiveness in removing certain targeted pollutants. This way, these techniques can be used in tandem with other non-selective methods, thus obtaining efficiency and cost effectiveness.

Among the separation and remediation techniques, polymeric adsorbents are some of the most efficient and widely applied in separation processes (Kwon et al. 2000; Shentu et al. 2007; Wang et al. 2001). They can be of varying configurations, but mainly consist of a polymer backbone and a ligand pendant on the backbone. Metal ions are usually bound to the polymer ligand by a coordinate bond (Kaliyappan and Kannan 2000). The advantage of this chemistry is that a selective removal can be achieved by choosing a suitable polymer ligand to target a specific metal.

It was demonstrated in our previous articles that phosphate and sulphate functional groups substituted in the backbone of polyethylenimine act as strong adsorption sites for removing specific metals in solution (Saad et al. 2012a, b). This study was aimed at developing a polymeric adsorbent based on a 
thiol functional group for selective removal of $\mathrm{Hg}$ from aqueous systems. $\mathrm{Hg}$ exposure can affect kidney functions, the central nervous system, and mental system. As such, its removal from environmental systems has become a research priority (Manohar et al. 2002; Rio and Delebarre 2003; Wahi et al. 2009; Cai and Jia 2010).

Cross-linked polyethylenimine was functionalized with ethylene sulphide $\left(\mathrm{C}_{2} \mathrm{H}_{4} \mathrm{~S}\right)$ for targeted $\mathrm{Hg}$ (II) complexation.

This study gives a background to a wider study intended to introduce polymers of this type for use in household filter systems. It has emerged that, due to the scarcity of water, certain households around Johannesburg use minepolluted groundwater as a source of drinking water. This is common in small plot holdings and farms (Dr. Carl Albrecht, Cancer South Africa, personal communication). Such water has been found to contain $\mathrm{Hg}$ and other toxic elements (Lusilao-Makiese et al. 2012). Another configuration would be to pack the polymer into small columns that can be placed in household containers (e.g. water jars) and left to contact with polluted water, allowing mass transfer of the $\mathrm{Hg}$ to the adsorbent in the column.

To assess the stability of the thiolated CPEI (TCPEI) for the above-mentioned purposes, the effects of some parameters on adsorption of $\mathrm{Hg}(\mathrm{II})$ were studied, namely $\mathrm{pH}$, adsorbent amount, contact time, and the presence of competing ions. Regeneration of the polymer was also done so as to assess its re-usability.

\section{Materials and methods}

Materials

All the reagents and solutions were prepared using reagentgrade chemicals from Sigma-Aldrich (South Africa) without further purification.
Cross-linked polyethylenimine (synthesis reported by Saad et al. 2011) and ethylene sulphide were used for the synthesis of TCPEI. The $\mathrm{Hg}$ (II) solutions were prepared from $\mathrm{Hg}\left(\mathrm{NO}_{3}\right)_{2}$. Competing metal ion solutions were prepared from their nitrate salts, namely $\mathrm{Zn}\left(\mathrm{NO}_{3}\right)_{2}, \mathrm{~Pb}\left(\mathrm{NO}_{3}\right)_{2}$, $\mathrm{Co}\left(\mathrm{NO}_{3}\right)_{2}, \mathrm{Cu}\left(\mathrm{NO}_{3}\right)_{2}, \mathrm{Fe}\left(\mathrm{NO}_{3}\right)_{3} \mathrm{H}_{2} \mathrm{O}$, and $\mathrm{Ni}\left(\mathrm{NO}_{3}\right)_{2}$. Adjustments of $\mathrm{pH}$ for the adsorption experiments were conducted using $1 \mathrm{~mol} \mathrm{~L}^{-1}$ solutions of $\mathrm{HNO}_{3}$ and $\mathrm{NaOH}$. Deionised water (Millipore) was used for the preparation of all solutions.

Synthesis of thiolated cross-linked polyethylenimine (TCPEI)

Cross-linked polyethylenimine (CPEI) of $5 \mathrm{~g}$ was dissolved in $100 \mathrm{~mL}$ of water, and the $\mathrm{pH}$ of the solution was adjusted to 7 . The solution was purged with nitrogen for $20 \mathrm{~min}$ followed by the addition of $1.73 \mathrm{~mL}$ of ethylene sulphide. The reaction mixture was then kept overnight under reflux at $90{ }^{\circ} \mathrm{C}$. The collected product was rinsed with abundant deionised water and dried in an oven. The thiolation reaction scheme is shown in Fig. 1.

Fourier Transform Infra Red spectroscopy was used to characterise the thiolated derivative of cross-linked polyethylenimine (TCPEI) to confirm the introduction of thiol group. The content of sulphur in the synthesised polymer was determined using LECO-932 CHNS analyser from LECO Corporation (Michigan, USA).

\section{Batch adsorption studies}

Batch adsorption experiments were conducted using a 1,000- $\mathrm{mg} \mathrm{L}^{-1}$ stock standard solution of $\mathrm{Hg}\left(\mathrm{NO}_{3}\right)_{2}$ from which $40 \mathrm{mg} \mathrm{L}^{-1}$ working standard solutions were obtained by serial dilution. This concentration was arbitrarily chosen as it represents a "worst-case" scenario of pollution by most toxic elements (e.g. mercury, uranium,

Fig. 1 Thiolation reaction scheme

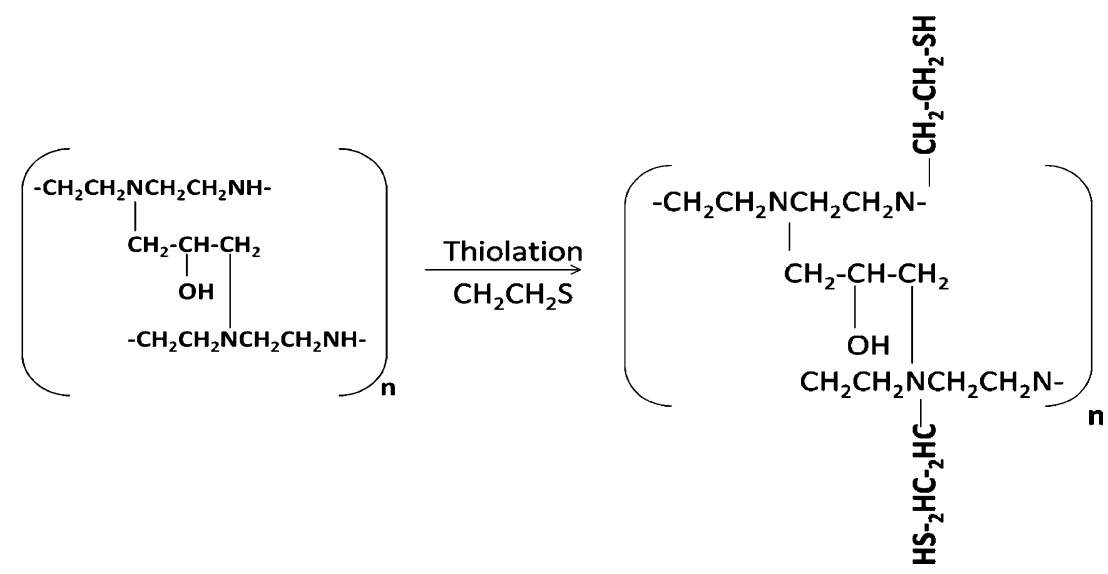


arsenic and vanadium) in mining-impacted waters in the Witwatersrand Basin goldfields (Tutu et al. 2009).

Adsorption experiments were performed in $50 \mathrm{~mL}$ flasks at room temperature. Different amounts of synthetic TCPEI were weighed out into each flask to assess the optimum amount of the adsorbent; $40 \mathrm{~mL}$ of $40 \mathrm{mg} \mathrm{L}^{-1}$ solution of $\mathrm{Hg}\left(\mathrm{NO}_{3}\right)_{2}$ standard was then added to each flask and stirred using magnetic stirrer. Adsorption at different $\mathrm{pH}$ values was assessed. At equilibrium, the solutions were filtered and the equilibrium concentrations were determined using an inductively coupled plasma optical emission spectroscopy (ICP-OES) (Genesis Spectro, Germany). The same procedure was followed using the multi-component solution to assess the effect of competing ions. The amount of ions adsorbed per unit mass of adsorbent was calculated on the basis of the mass balance equation:

$q_{\mathrm{e}}=\frac{\left(C_{\mathrm{i}}-C_{\mathrm{f}}\right) \times V}{(1000 \times P)}$

where $q_{\mathrm{e}}$ (mg metal $\mathrm{g}^{-1}$ polymer) is the adsorption capacity, $C_{\mathrm{i}}\left(\mathrm{mg} \mathrm{L}^{-1}\right)$ is the initial concentration of $\mathrm{Hg}(\mathrm{II})$ in the solution, $C_{\mathrm{f}}\left(\mathrm{mg} \mathrm{L}^{-1}\right)$ the concentration of $\mathrm{Hg}(\mathrm{II})$ in the filtrate, $V(\mathrm{~mL})$ the volume of initial solution and $P(\mathrm{~g})$ is the amount of polymer used.

Effect of adsorbent amount

The amount of adsorbent was optimised to obtain the optimal removal. Adsorption experiments were conducted using different amounts of TCPEI, namely 0.03, 0.05, 0.1, $0.2,0.5$, and $1.0 \mathrm{~g}$, and synthetic standard mercury solutions of $40 \mathrm{mg} \mathrm{L}^{-1}$ at room temperature and fixed time.

\section{Effect of contact time}

Adsorption experiments were conducted at room temperature $\left(27^{\circ} \mathrm{C}\right)$ to obtain the optimal time required for adsorption. Adsorption was studied at various time intervals (10-120 min) and fixed concentration $\left(40 \mathrm{mg} \mathrm{L}^{-1}\right)$. The concentration of $\mathrm{Hg}$ (II) was determined at the end of each time. The obtained equilibrium capacities $\left(q_{\mathrm{e}}\right)$ were then plotted against the equilibrium time for kinetic modelling.

\section{Desorption studies}

Desorption of $\mathrm{Hg}$ (II) from TCPEI was studied by treating the previously loaded polymer with an excess of extracting reagent. $\mathrm{HNO}_{3}$ at different concentrations, namely 2, 3, 5, and $7 \mathrm{~mol} \mathrm{~L}^{-1}$, was used as an extractant. During regeneration, the mixtures were stirred for $1 \mathrm{~h}$, filtered and the polymer washed with deionised water and dried prior to reuse, while the filtrates were analyzed by ICP-OES.
All experiments were repeated three times $(n=3)$, and the limit of detection (LOD) was calculated as $3 \times$ standard deviation of the blank and the method quantitation limit (MQL) was calculated as $10 \times$ standard deviation of the blank.

Modelling of analytical results

The results from adsorption studies were modelled using kinetic (pseudo-first-order and pseudo-second-order
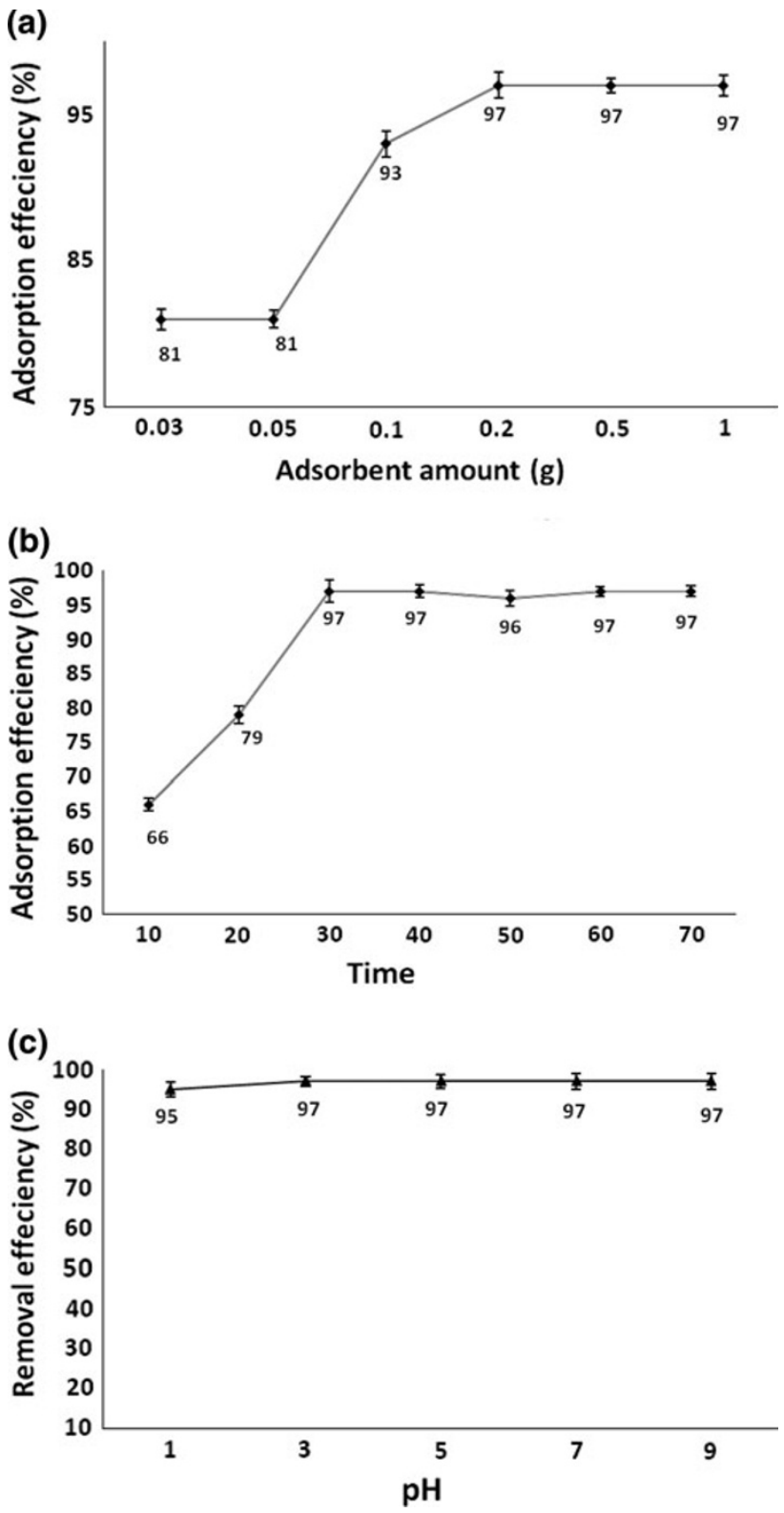

Fig. 2 Effect of adsorbent amount (a), contact time (b), and pH (c) on the adsorption process. Initial concentrations $=40 \mathrm{mg} \mathrm{L}^{-1}$, contact time $=30 \mathrm{~min}$, at $\mathrm{pH} 3$ and room temperature $\left(27^{\circ} \mathrm{C}\right)$. Initial concentrations $=40 \mathrm{mg} \mathrm{L}^{-1}$, adsorbent amount $=0.2 \mathrm{~g}$, at $\mathrm{pH} 3$ and room temperature $\left(27^{\circ} \mathrm{C}\right)$. Initial concentrations $=40 \mathrm{mg} \mathrm{L}^{-1}$, contact time $=30 \mathrm{~min}$, adsorbent amount $=0.2 \mathrm{~g}$, at room temperature $\left(27^{\circ} \mathrm{C}\right)$ 
Table 1 Removal efficiencies of elements in a multi-component solution

\begin{tabular}{lllllllll}
\hline & $\mathrm{Hg}$ & $\mathrm{Co}$ & $\mathrm{Cu}$ & $\mathrm{Se}$ & $\mathrm{Pb}$ & $\mathrm{Zn}$ & $\mathrm{Ni}$ & $\mathrm{Fe}$ \\
\hline$C_{\mathrm{f}}\left(\mathrm{mg} \mathrm{L}^{-1}\right)$ & 1.1 & 4.9 & 5.1 & 29.1 & 7.6 & 8.3 & 9.1 \\
Rsd & 0.678 & 3.33 & 1.857 & 1.9 & 2.76 & 2.693 & 2.013 \\
Capacity $\left(\mathrm{mg} \mathrm{g}^{-1}\right)$ & 7.78 & 7.02 & 6.98 & 0.436 & 6.48 & 6.34 & 6.18 & 2.002 \\
Efficiency (\%) & 97 & 88 & 87 & 28 & 81 & 79 & 77 & 0.724 \\
LOD & 0.002 & 0.024 & 0.003 & 0.001 & 0.034 & 0.090 & 0.081 \\
MQL & 0.001 & 0.001 & 0.026 & 0.067 & 0.054 & 0.022 & 0.003 & 0.050 \\
\hline
\end{tabular}

Initial concentration of the ions $=40 \mathrm{mg} \mathrm{L}^{-1}$

$C_{f}$ Final concentration after adsorption, $R S D$ relative standard deviation $(n=3), L O D$ limit of detection in $\mathrm{mg} \mathrm{L}^{-1}, M Q L$ method quantitation limit in $\mathrm{mg} \mathrm{L}^{-1}$

equations), isotherms (Langmuir and Freundlich), and thermodynamic models.

Speciation modelling of the metal ions in solution was conducted using MEDUSA software (KTH Royal Institute of Technology, Sweden).

\section{Kinetic models}

The kinetic models that were used to fit the experimental data are as follows.

The pseudo first-order model was defined by the equation

$\log \left(q_{\mathrm{e}}-q_{t}\right)=\log q_{\mathrm{e}}-\left(k_{1} / 2.303\right) t$

The plot of $\log \left(q_{\mathrm{e}}-q_{t}\right)$ vs. $t$ gives a straight line.

The pseudo-second-order model was defined by the equation

$1 / q_{t}=\left(1 / k_{2} q_{\mathrm{e}}^{2}\right)+\left(1 / q_{\mathrm{e}}\right) t$

The plot of $t / q_{t}$ vs. $t$ gives a straight line.

The parameters in the above equations are defined as follows: $q_{\mathrm{e}}\left(\mathrm{mg} \mathrm{g}^{-1}\right)$ is the adsorption capacity at equilibrium, $q_{t}\left(\mathrm{mg} \mathrm{g}^{-1}\right)$ is the adsorption capacity at time $t$, and $k_{1}$ and $k_{2}(1 / \mathrm{min})$ are the rate constants for the pseudo-firstorder and pseudo-second-order models, respectively. These are obtained from the slope of the plot of $\log \left(q_{\mathrm{e}}-q_{t}\right)$ vs. $t$.

\section{Isotherm models}

Adsorption isotherms describe the nature of the adsorbentadsorbate interaction as well as the specific relation between the concentration of adsorbate and its degree of accumulation onto the adsorbent surface (Gupta et al. 2003; $\mathrm{Li}$ et al. 2008). To understand the adsorption mechanism of $\mathrm{Hg}$ (II) onto the TCPEI surface, two adsorption isotherm models, Langmuir and Freundlich were used to fit the experimental data (Cozmuta et al. 2012; Freundlich 1926). The experimental data for isotherm modelling were obtained by conducting the adsorption experiments using $1 \mathrm{~g}$ of TCPEI and $40 \mathrm{~mL}$ solutions of different $\mathrm{Hg}$ (II) concentrations under continuous stirring. At equilibrium, the solutions were filtered and the non-adsorbed $\mathrm{Hg}(\mathrm{II})$ was determined.

The Langmuir model is given by the following equation:

$q_{\mathrm{e}}=\frac{q_{\mathrm{m}} b C_{\mathrm{e}}}{1+b C_{\mathrm{e}}}$

where $q_{\mathrm{e}}\left(\mathrm{mg} \mathrm{g}^{-1}\right)$ is the amount adsorbed per unit weight of adsorbent at equilibrium, $C_{\mathrm{e}}\left(\mathrm{mg} \mathrm{L}^{-1}\right)$ is the equilibrium concentration of the adsorbate, and $q_{\mathrm{m}}\left(\mathrm{mg} \mathrm{g}^{-1}\right)$ is the maximum adsorption capacity, and $b\left(\mathrm{~L} \mathrm{mg}^{-1}\right)$ is the constant related to the free energy of adsorption. The values of maximum capacity $\left(q_{\mathrm{m}}\right)$ and Langmuir constant (b) were calculated from the intercept and the slope of the plots.

The Freundlich model given by the following equation:

$q_{\mathrm{e}}=K_{\mathrm{F}} C_{\mathrm{e}}^{1 / n}$

where $K_{\mathrm{F}}\left(\mathrm{mg}^{1-(1 / n)} \mathrm{L}^{1 / n} \mathrm{~g}^{-1}\right)$ is a constant correlated to the relative adsorption capacity of the adsorbent and $n$ is a constant indicative of the intensity of the adsorption.

\section{Thermodynamic modelling}

The thermodynamic study was done by conducting the adsorption experiments at two different temperatures (15 and $27^{\circ} \mathrm{C}$ ). The concentrations obtained after adsorption were then used to calculate the activation energy $\left(E_{\mathrm{a}}\right)$ according to the Arrhenius equation:

$E_{\mathrm{a}}=\frac{R \times T_{1} T_{2} \ln \left(\frac{k_{2}}{k_{1}}\right)}{T_{1}-T_{2}}$

where $E_{\mathrm{a}}$ is the activation energy, $R$ is the gas constant; $T_{1}$ and $T_{2}$ are the two different temperatures; $k_{1}$ and $k_{2}$ are rate constants for the two temperatures.

The constants $k_{1}$ and $k_{2}$ were calculated using the pseudo-second-order equation at each temperature.

The magnitude of the activation energy gives an idea about the type of adsorption, namely physisorption (usually 
Fig. 3 Comparison between $\mathrm{pH}$ dependency of $\mathrm{Hg}(\mathrm{II})$ and competing ions removal. Initial adsorbent amount $=0.2 \mathrm{~g}$, temperature $\left(27^{\circ} \mathrm{C}\right)$ concentrations $=40 \mathrm{mg} \mathrm{L}^{-1}$, contact time $=30 \mathrm{~min}$ at room

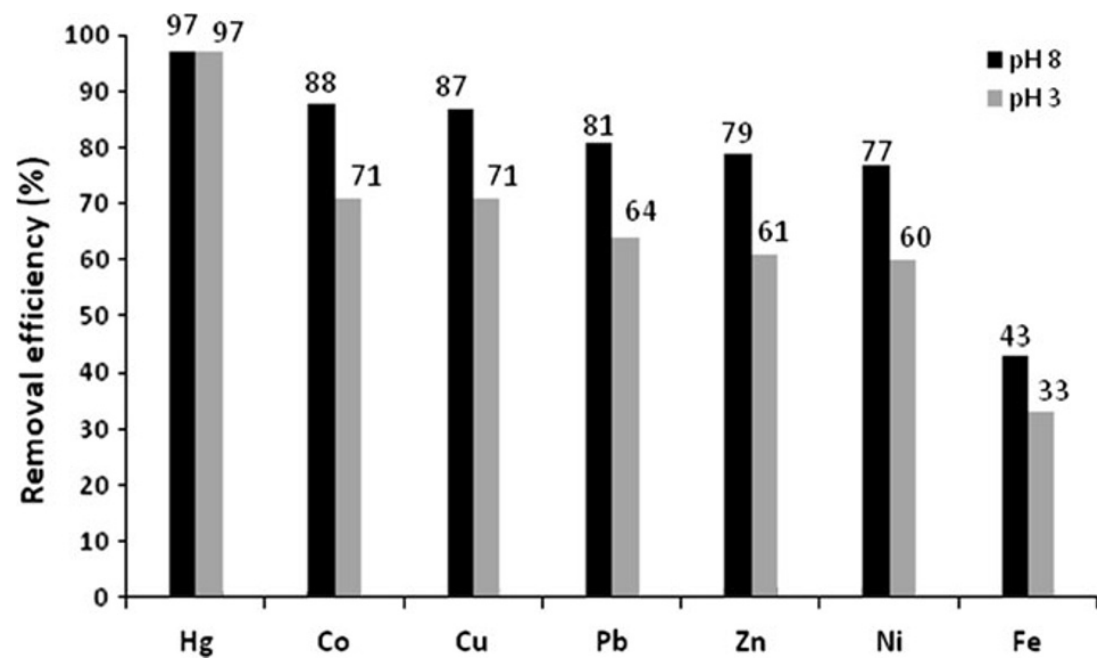

no more than $4.2 \mathrm{~kJ} \mathrm{~mol}^{-1}$ ) or chemisorption (Klekamp and Urnbac 1993; Özcan et al. 2006).

\section{Results and discussion}

Characterisation of thiolated cross-linked polyethylenimine

Sulphur content could be used as an indicator of the thiolation of the polymer since polyethylenimine only contains $\mathrm{C}, \mathrm{N}$, and $\mathrm{H}$. The results from CHNS analysis confirmed the introduction of the thiol group with a sulphur content of $9.1 \%$ being recorded.

IR characterisation confirmed the presence of the thiol group as the sharp peaks observed at 671.47 and $721.80 \mathrm{~cm}^{-1}$ which correspond to the stretching vibration of C-S (Coates 2000).

\section{Effect of adsorbent amount}

The results for the dependence of adsorption of $\mathrm{Hg}$ (II) on the amount of the polymer are shown in Fig. 2a.

The results showed that adsorption increased sharply from $81 \%$ with an adsorbent amount of 0.03 and $0.05 \mathrm{~g}$, $93 \%$ with $0.1 \mathrm{~g}$ of adsorbent, and increased and remained constant at $97 \%$ for $0.2-1 \mathrm{~g}$. Thus, $0.2 \mathrm{~g}$ was considered as the optimum adsorbent amount required for optimal adsorption.

\section{Effect of contact time}

The experimental runs measuring the effect of contact time on the adsorption of $\mathrm{Hg}$ (II) were conducted at various time intervals between 10 and $120 \mathrm{~min}$ and at room temperature, $\mathrm{pH} \mathrm{7,} \mathrm{elemental} \mathrm{concentration} 40 \mathrm{mg} \mathrm{L}^{-1}$, and an

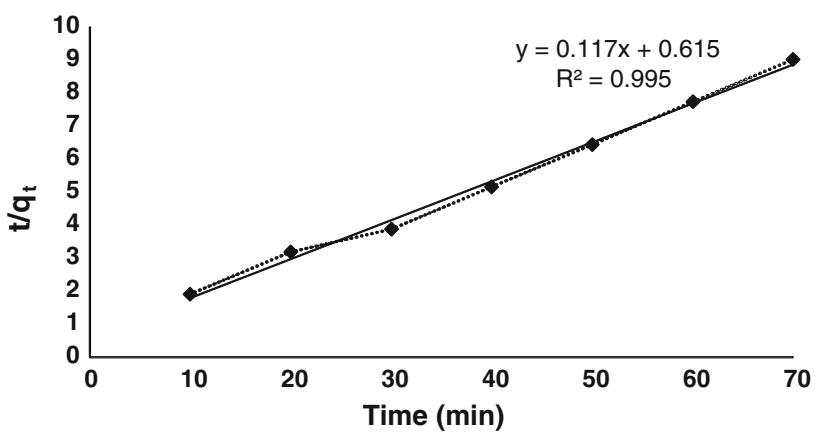

Fig. 4 Pseudo-second-order plot for the adsorption process. Initial concentrations $=40 \mathrm{mg} \mathrm{L}^{-1}$, adsorbent amount $=0.2 \mathrm{~g}$, at $\mathrm{pH} 3$ and room temperature $\left(27^{\circ} \mathrm{C}\right)$

adsorbent mass of $0.2 \mathrm{~g}$, to obtain the optimal time required for adsorption. The concentration of $\mathrm{Hg}$ (II) was determined at the end of each time. The obtained equilibrium capacities $\left(q_{\mathrm{e}}\right)$ were then plotted against the equilibrium time for kinetic modelling. Figure $2 b$ shows the effect of contact time on the adsorption of $\mathrm{Hg}$ (II).

Adsorption increased rapidly with an increase in contact time from 10 to $30 \mathrm{~min}$. A further increase in time had no effect on the adsorption. A maximum contact time of $30 \mathrm{~min}$ was therefore considered as the optimum time for adsorption.

\section{Effect of $\mathrm{pH}$}

Synthetic standard solutions of $40 \mathrm{mg} \mathrm{L}^{-1}$ with a fixed quantity of adsorbent, fixed time, and fixed temperature were used. The $\mathrm{pH}$ of the synthetic solutions was adjusted to five different $\mathrm{pH}$ values, namely $1,3,5,7$, and 9 , using $1 \mathrm{~mol} \mathrm{~L}{ }^{-1}$ sodium hydroxide and $1 \mathrm{~mol} \mathrm{~L}^{-1}$ hydrochloric acid. Figure $2 \mathrm{c}$ shows adsorption at different $\mathrm{pH}$ values.

The adsorption percentages showed high removal efficiency independent of $\mathrm{pH}$. This independence of the 
adsorption of $\mathrm{Hg}(\mathrm{II})$ on the $\mathrm{pH}$ could hinge on the high affinity of the $\mathrm{Hg}$ (II) to thiol group on the polymer surface, as such outperforming the hydrogen ions.

\section{Effect of competing ions}

To investigate the selectivity of TCPEI towards $\mathrm{Hg}$ (II), adsorption experiments were performed in the presence of competing ions using multi-component standard solutions containing $\mathrm{Co}(\mathrm{II}), \mathrm{Cu}$ (II), $\mathrm{Pb}$ (II), $\mathrm{Zn}$ (II), $\mathrm{Ni}(\mathrm{II}), \mathrm{Fe}(\mathrm{III})$, and $\mathrm{Hg}(\mathrm{II})$ at $\mathrm{pH} 7.3$ and adsorbent amount of $0.2 \mathrm{~g}$. Table 1 shows the final metal concentrations obtained after adsorption from an initial concentration of $40 \mathrm{mg} \mathrm{L}^{-1}$ for all metals. The adsorption capacity, efficiency (\%) and the relative standard deviation (RSD) are based on three measurements $(n=3)$.

TCPEI showed good removal efficiency for all metals except Fe. However, the removal of $\mathrm{Hg}$ (II) was still the highest. The effect of competing ions was further studied at low $\mathrm{pH}$ of 3 to assess the effect of $\mathrm{pH}$ on the removal of $\mathrm{Hg}(\mathrm{II})$ in the presence of other elements. Figure 3 shows the removal efficiency of elements in a multi-component solution in acidic and basic conditions.

The results show that the removal of $\mathrm{Hg}$ (II) by TCPEI was independent of $\mathrm{pH}$, whereas that of other ions was highly dependent. From speciation modelling using MEDUSA, the following species were found to be dominant at $\mathrm{pH}$ 3: $\mathrm{Hg}^{2+}, \mathrm{Co}^{2+}, \mathrm{Cu}^{2+}, \mathrm{Pb}^{2+}, \mathrm{Zn}^{2+}, \mathrm{Ni}^{2+}, \mathrm{Fe}^{3+}$ and $\mathrm{FeOH}^{2+}$. At pH 8, the following species were observed to be dominant: $\mathrm{HgOH}^{+}, \mathrm{Hg}(\mathrm{OH})_{2} ; \mathrm{CoOH}^{+}, \mathrm{Co}(\mathrm{OH})_{2}$, $\mathrm{Cu}(\mathrm{OH})_{2}, \mathrm{~Pb}(\mathrm{OH})_{2}, \mathrm{Zn}(\mathrm{OH})_{2}, \mathrm{Ni}(\mathrm{OH})_{2}$ and $\mathrm{Fe}(\mathrm{OH})_{3}$. It can be observed that, at $\mathrm{pH} 3$, the metals exist as divalent ions in solution. Thus, any adsorption is influenced by the affinity of the metal to the adsorbent surface. This binding is based on the hard-soft Lewis acid-base theory where the sulphur on the thiolated polymer acts as a Lewis base and binds the metal (Lewis acid) by a coordinate bond (Pearson 1968). Since $\mathrm{Hg}(\mathrm{II}), \mathrm{Co}(\mathrm{II})$ and $\mathrm{Cu}(\mathrm{II})$ are soft acids, they tend to preferentially bind to sulphur (a soft base) compared to other metals. However, the affinity of thiol to $\mathrm{Hg}$ (II) is superior compared to that for $\mathrm{Co}(\mathrm{II})$ and $\mathrm{Cu}(\mathrm{II})$, a property that has earned thiol the name mercaptan or mercury capturing (Dujardin et al. 2000). Ni(II), Zn(II) and $\mathrm{Pb}$ (II) showed good adsorption as well since they are considered moderate acids (or borderlines acids) and as such they can bind to either soft or hard bases (Pearson 1968). Fe(III), on the other hand, is a hard acid, hence its low removal efficiency. At $\mathrm{pH} 8$, it can be observed that the metals, except partly for $\mathrm{Hg}$ and $\mathrm{Co}$, are completely hydrolysed and form precipitates. Their adsorption at this $\mathrm{pH}$ is largely due to precipitation, while that for $\mathrm{Hg}$ and $\mathrm{Co}$ could be due to the combination of both precipitation and interaction of $\mathrm{HgOH}^{+}$and $\mathrm{CoOH}^{+}$with sulphur.
Kinetic modelling of adsorption process

The high correlation obtained by plotting the linearised form of pseudo-second-order model $\left(R^{2}=0.995\right)$ compared to that for the pseudo-first-order model $\left(R^{2}=0.758\right)$ demonstrated that the former gives a better fit, implying that the adsorption occurs via a chemisorption process (Antures et al. 2003). A plot of the linearised form of pseudo-second-order model ( $t / q_{t}$ vs. $\left.t\right)$ is given in Fig. 4.

Adsorption isotherms

The results from isotherm modelling suggest that the Freundlich model fits the data better as shown by the correlation coefficient of 0.963 , whereas that for the Langmuir correlation coefficient is 0.536 . This result demonstrates adsorption on a heterogeneous surface. It also assumes that the adsorption capacity of the adsorbent increases with increasing concentration of the adsorbate.

\section{Thermodynamic studies}

The calculated activation energy value $\left(E_{\mathrm{a}}\right)$ for the adsorption of $\mathrm{Hg}$ (II) onto TCPEI surface was $55.97 \mathrm{~kJ} \mathrm{~mol}^{-1}$. This elevated value implies that $\mathrm{Hg}(\mathrm{II})$ is adsorbed onto the TCPEI via a chemisorption process which is consistent with the results obtained from kinetic modelling. $k_{1}$ and $k_{2}$ values are 0.027 and 0.021 , respectively.

\section{Desorption studies}

Desorption results for TCPEI by different nitric acid concentrations are shown in Fig. 5. The results show the concentrations of $\mathrm{Hg}(\mathrm{II})$ desorbed by 2, 3, 5, and $7 \mathrm{~mol} \mathrm{~L}^{-1}$ of $\mathrm{HNO}_{3}$.

The desorbed amount of $\mathrm{Hg}(\mathrm{II})$ increased with increasing $\mathrm{HNO}_{3}$ concentration from $3.3 \mathrm{mg} \mathrm{L}{ }^{-1}$ of $2 \mathrm{~mol} \mathrm{~L}^{-1} \mathrm{HNO}_{3}$ to $31 \mathrm{mg} \mathrm{L}^{-1}$ of $5 \mathrm{~mol} \mathrm{~L}^{-1} \mathrm{HNO}_{3}$, with no further

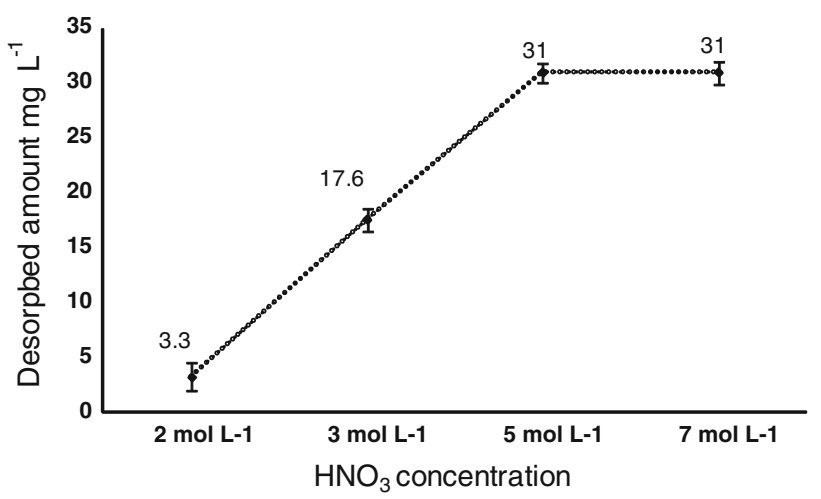

Fig. 5 Desorption of $\mathrm{Hg}$ from TCPEI by different $\mathrm{HNO}_{3}$ concentrations 


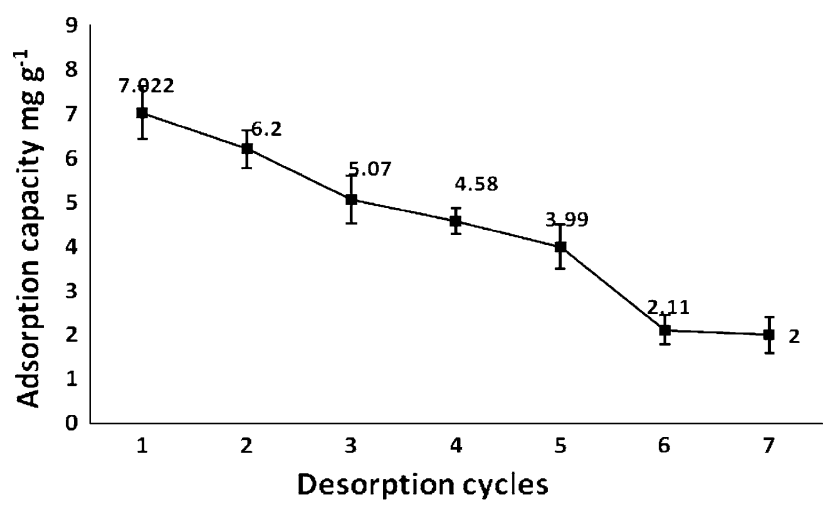

Fig. 6 Adsorption capacity after several subsequent desorptions. Initial concentrations $=40 \mathrm{mg} \mathrm{L}{ }^{-1}$, adsorbent amount $=0.2 \mathrm{~g}$, contact time $=30 \mathrm{~min}$ at $\mathrm{pH}=3$ and room temperature $\left(27^{\circ} \mathrm{C}\right)$

desorption beyond that. Subsequently, regeneration of TCPEI was carried out using $5 \mathrm{~mol} \mathrm{~L}^{-1}$ acid concentration.

The regenerated TCPEI showed $88 \%$ removal efficiency and $7.022 \mathrm{mg} \mathrm{g}^{-1}$ removal capacity after one cycle of desorption. This is a lower efficiency compared to that for a fresh polymer (dropped by $9 \%$ ), which was still good.

Serial desorptions were conducted to assess the amount of intractable $\mathrm{Hg}(\mathrm{II})$ that would remain bound to the polymer. For example, after seven desorption cycles (Fig. 6), the amount of $\mathrm{Hg}(\mathrm{II})$ adsorbed onto TCPEI dropped by $5.48 \mathrm{mg} \mathrm{g}^{-1}$ (from $7.78 \mathrm{mg} \mathrm{g}^{-1}$ for the fresh polymer to $2.00 \mathrm{mg} \mathrm{g}^{-1}$ after the seventh desorption). The decrease of the removal efficiency could be attributed to the fact that, after each desorption process, there will be an amount of $\mathrm{Hg}(\mathrm{II})$ that would remain bound to the polymer surface and hence reduce the available sites for adsorption. The removal efficiency decreased in the following percentages: $97>88>78>63>57>50>26>25$. This suggests that TCPEI could be efficiently re-usable up to five cycles, beyond which the removal efficiency drops below $50 \%$.

Generally, the results obtained from this study showed that the performance of TCPEI outperforms other reported adsorbents in terms of selectivity and $\mathrm{pH}$ dependency. Sreedhar and Anirudhan (1999) studied the removal of $\mathrm{Hg}$ using polyacrylamide grafted onto sawdust which had a superior removal capacity, but this was more dependent on the $\mathrm{pH}$ (less removal efficiency was observed at $\mathrm{pH}$ below 5.5). This limits the use of the adsorbent for $\mathrm{Hg}$ recovery from low $\mathrm{pH}$ solutions, e.g. AMD-impacted waters in which $\mathrm{pH}$ can be lower than 3. Moreover, the removal procedure was time consuming, taking $5 \mathrm{~h}$ to reach the optimum removal. Another study by Kesenci et al. (2002) demonstrated very fast adsorption using poly(ethyleneglycol dimenthacrylate-co-acrylamide) beads, where the largest amount of $\mathrm{Hg}$ was attached to the adsorbent within the first $10 \mathrm{~min}$ with saturation gradually reached within $30 \mathrm{~min}$. Beside the advantage of the fast kinetics, it also showed some demerits such as the high dependency on the $\mathrm{pH}$ as well as the poor selectivity towards $\mathrm{Hg}$ in the presence of $\mathrm{Pb}$.

Rio and Delebarre (2003) also reported the removal of $\mathrm{Hg}$ using silico-aluminous fly ashes and sulfo-calcic fly ashes. They obtained removal efficiencies of 54 and $81 \%$, respectively. According to their explanation, the difference on the removal efficiency is based on the chemical composition of two fly ashes, in which the one with high removal efficiency contains more sulphur than the other one with poor removal. However, in both cases, the removal process was time consuming, taking $72 \mathrm{~h}$ to reach the equilibrium, while in our case, this was achieved in $30 \mathrm{~min}$.

Liu and Guo (2006) reported the removal of Hg using polyacrylamide-grafted attapulgite (PAM-ATP) with removal capacity of $1.12 \mathrm{mg} \mathrm{g}^{-1}$, which is quite similar to the results of this study. On other hand, some differences in terms of efficiency, selectivity, influencing of different conditions such as $\mathrm{pH}$, and time were demonstrated.

In another study by the authors (Saad et al. 2012b), good efficiency of sulphonated cross-linked polyethylenimine was reported with up to $87 \%$ removal of $\mathrm{Hg}(\mathrm{II})$, but $\mathrm{Se}$ was found to highly compete with $\mathrm{Hg}$ (II). In this sense, TCPEI represents a good alternative for $\mathrm{Hg}$ (II) removal considering its high selectivity and independence of $\mathrm{pH}$, thus making it an efficient adsorbent for the intended application of this study.

\section{Conclusions}

A new, efficient polyethylenimine derivative has been developed by thiolation and successfully employed for the removal of mercury from aqueous solutions under optimal conditions, namely $30 \mathrm{~min}$ contact time, $40 \mathrm{mg} \mathrm{L}^{-1}$ initial concentration, and $0.2 \mathrm{~g}$ adsorbent amount.

The modified polymer showed high efficiency and selectivity towards $\mathrm{Hg}$ (II) independent of $\mathrm{pH}$ and competing ions, thus outperforming most of the reported adsorbents for $\mathrm{Hg}$ capture.

The Freundlich isotherm was found to be the best fit describing the experimental data, suggesting that adsorption occurred on a heterogeneous surface. The pseudosecond-order model was found to explain the adsorption kinetics most effectively. This model and the results of the thermodynamic study showed that $\mathrm{Hg}(\mathrm{II})$ adsorption occurred via chemisorption.

The possibility of re-using the developed polymer is also a very significant factor especially with respect to cost effectiveness of the removal process. 
Open Access This article is distributed under the terms of the Creative Commons Attribution License which permits any use, distribution, and reproduction in any medium, provided the original author(s) and the source are credited.

\section{References}

Ahmed I, Ghonaim A, Abdel Hakim A, Moustafa M, Kamal El-Din A (2008) Synthesis and characterization of polymers for removing of some heavy metal ions of industrial wastewater. J Appl Sci Res 4:1946-1958

Antures W, Luna A, Henriques C, Costa A (2003) An evaluation of copper biosorption by a brown seaweed under optimized conditions. Electron J Biotechnol 6:174-184

Cai JH, Jia CQ (2010) Mercury removal from aqueous solution using coke-derived sulfur-impregnated activated carbons. J Ind Eng Chem Res 49:2716-2721

Coates J (2000) Interpretation of infrared spectra, a practical approach. Encyclopedia of Analytical Chemistry. Meyers RA (ed.) pp 10815-10837

Cozmuta LM, Cozmuta AM, Peter A, Nicula C, Bakatula E, Tutu H (2012) The influence of $\mathrm{pH}$ on the adsorption of lead by Naclinoptilolite: kinetic and equilibrium studies. Water SA 38:269-272

Dujardin MC, Caze C, Vroman I (2000) Ion-exchange resins bearing thiol groups to remove mercury. Part 1: synthesis and use of polymers prepared from thioester supported resin. J React Funct Polym 43:123-132

Freundlich H (1926) Adsorption. J Phys Chem 7:57-64

Ghoul M, Bacquet M, Morcellet M (2003) Uptake of heavy metals from aqueous solutions using modified PEI-silica gels. J Water Res 37:729-734

Gupta V, Jain C, Ali J, Sharma M, Saini V (2003) Removal of cadmium and nickel from wastewater using bagasse fly ash-a sugar industry waste. J Water Res 37:4038-4044

Hang X, Wang H, Zhou J, Du C, Chen X (2009) Characteristics and accumulation of heavy metals in sediments originated from an electroplating plant. J Hazard Mater 163:922-930

Kaliyappan T, Kannan P (2000) Coordination polymers. J Prog Polym Sci 25:343-370

Kesenci K, Say R, Denizli A (2002) Removal of heavy metal ions from water by using poly (ethyleneglycol dimethacrylate-coacrylamide) beads. Eur Polym J 38:1443-1448

Klekamp A, Unbac E (1993) Physisorption on an epitaxial $\mathrm{NaCl}(100)$ double-layer: SF6 and xenon. J Surf Sci 284:291-304

Kwon W, Yoo C, Chang W, Noh Y, Suh J (2000) Metal sequestering by a poly (ethyleninimine)-sephadex G-25 conjugate containing 2,2-dihydroxyazobenzene. J Bull Korean Chem Soc 21:393-400

Li C, Cheng C, Choo K, Yen W (2008) Polyelectrolyte enhanced ultrafiltration (PEUF) for the removal of Cd(II): effects of organic ligands and solution $\mathrm{pH}, \mathrm{J}$. Chemosphere 72:630-635
Liu P, Guo J (2006) Polyacrylamide grafted attapulgite (PAM-ATP) via surface-initiated atom transfer radical polymerization (SIATRP) for removal of $\mathrm{Hg}(\mathrm{II})$ ion and dyes. J Coll Surf 282-283:498-503

Lusilao-Makiese J, Tessier E, Amouroux D, Tutu H, Chimuka L, Cukrowska E (2012) Speciation of mercury in South African coals. J Toxicol Environ Chem 4:1688-1706

Manohar DM, Krishnan KA, Anirudhan TS (2002) Removal of mercury (II) from aqueous solutions and chlor-alkali industry wastewater using 2-mercaptobenzimideazole-clay. J Water Res 36:1609-1619

Özcan A, Öncü E, Özcan A (2006) Kinetics, isotherm and thermodynamic studies of adsorption of Acid Blue 193 from aqueous solutions onto natural sepiolite. J Coll Surf 277:90-97

Pearson R (1968) Hard and soft acids and bases, HSAB, part 1: fundamental principles. J Chem Educ 45:581-587

Rio S, Delebarre A (2003) Removal of mercury in aqueous solution by fluidized bed plant fly ash. J Fuel 82:153-159

Saad DM, Cukrowska EM, Tutu H (2011) Development and application of cross-linked polyethylenimine for trace metal and metalloid from mining and industrial wastewaters. J Toxicol Environ Chem 93:914-924

Saad DM, Cukrowska EM, Tutu H (2012a) Phosphonated crosslinked polyethylenimine for selective removal of uranium ions from aqueous solutions. J Water Sci Technol 66:122-129

Saad DM, Cukrowska EM, Tutu H (2012b) Sulphonated cross-linked polyethylenimine for selective removal of mercury from aqueous solutions. J Toxicol Environ Chem 94:1916-1929

Shentu B, Zhu Q, Liu Q, Weng Z (2007) Kinetics and equilibrium of cobalt ion adsorption on cross-linked polyethylenimine membrane. J Appl Polym Sci 105:1964-1967

Sreedhar MK, Anirudhan TS (1999) Preparation of an adsorbent by graft polymerization of acrylamide onto coconut husk for mercury (II) removal from aqueous solution and chloralkali industry wastewater. J Appl Polym Sci 75:1261-1269

Tutu H, Cukrowska E, McCarthy T, Hart R, Chimuka L (2009) Radioactive disequilibrium and geochemical modelling as evidence of uranium leaching from gold tailing dumps in the Witwatersrand Basin. J Environ Anal Chem 89:687-703

Velea T, Gherghe L, Krebs R, Predicam V (2008) Heavy metal contamination in the vicinity of an industrial area near Bucharest. J Environ Sci Pollut Res 16:27-32

Wahi R, Ngaini Z, Jok V (2009) Removal of mercury, lead and copper from aqueous solution by activated carbon of palm empty fruit bunch. J World Appl Sci 5:84-91

Wang C, Chen C, Chang C (2001) Synthesis of chelating resins with iminodiacetic acid and its wastewater treatment application. J Appl Polym Sci 84:1353-1362

Zhuang P, McBride M, Xia H, Li N, Li Z (2009) Health risks from heavy metals via consumption of food crops in the vicinity of Dabaoshan mine, South China. J Sci Total Environ 407:1551-1561 